\title{
Representative period of measurements for wind regime characterization in Dobrogea region, Romania
}

\author{
R. Pilão, P. Pinto, R. Guedes
}

A B S T R A C T

The proposed work aims to characterize the inter-annual variability of the mean wind speed for the Dobrogea region of Romania in order to determine the minimum local wind measurements period for its wind regime characterization.

To achieve this, wind data from local wind measurements at meteorological stations in operation over the past 6 years and installed in different sites of the region were analyzed.

In a second stage, the NCEP/NCAR reanalysis data base for that region was validated by comparison with the local measurements and the last 20 years were used for the characterization of the inter-annual variability of the mean wind velocity.

As expected, the data from local wind measurements indicate that the maximum deviation of the mean wind speed decreases continually with the increasing of the period used in their determination, although at a decreasing rate.

The use of reanalysis data for the period of the measurements made in the different sites showed that data from the NCEP/NCAR represent in an acceptable way the mean inter-annual variability for the measurement sites tested.

The findings point out that the industry standard figures for annual wind variability can be conservative for the Dobrogea region. This will have a direct impact on pre-construction estimates of wind farm production and on financing and debt rising for the projects.

For the Dobrogea region, the studied data pointed out that the inter-annual variability of mean annual wind speed could be much lower than typical wind industry standard figures.

Moreover, the evolution of inter-annual variability with the number of consecutive years of data appears slightly less conservative than the evolution typically assumed by the industry.

The test case presented highlighted the significant drop in the overall uncertainty on wind farm energy yield estimates between 1 and 2 years of observed wind data.

This study should be repeated for other regions with wind farm developments, quite specially those more distant from Central Europe/UK (where the industry standard practices were primarily derived). NCEP/NCAR reanalysis can be a very useful tool for this kind of studies (being freely available and global) but its use for inter-annual wind variability should be tested in each case.

Keywords:

Inter-annual variability

Long-term

NCEP/NCAR

Dobrogea

Romania

\section{Introduction}

Dobrogea is a region in Eastern Romania surrounded to the north and west by the Danube and to the east by the Danube Delta and the Black Sea.

The wind conditions in Dobrogea region have been monitored by the Portuguese consultancy company MEGAJOULE for more than 6 years on specially installed meteorological masts, employing the most up to date equipment for wind measurements. There are ongoing measurements on more than 20 sites, over the whole area.

The data collected during the last years enable us to propose this work which aims to characterize the inter-annual variability of the wind mean speed for the Dobrogea region of Romania in order to determine the minimum local wind measurements period for its characterization.

It is known that for the accurate evaluation of the wind potential of a given place its wind regime must be characterized and the Annual Mean Wind Speed assumes the major importance. To properly quantify this variable, local measurements must be undertaken for a representative period of time. 
No systematic studies to quantify the number of consecutive years of measurements needed for the complete characterization of the long-term wind speed in Romania are available. This information is of extreme importance to ensure an acceptable error in the wind resource evaluation at a given site.

This work presents the results of such a study carried out for the Eastern territory of Romania: Dobrogea.

\section{Industry standards regarding wind variability}

While the subject of wind variability plays indeed an important role in the uncertainty of wind assessments for prospects wind farms, it is still a fact that this issue has not been studied in depth in the past by the wind energy community.

Studies made by Troen and Petersen (1989) and published on the European Wind Atlas show that, in Portugal, in a set of 10 years, the Annual Mean Wind Speed (AMWS) of any 2 consecutive years has a deviation of no more than $5 \%$ (coefficient of variation, $\mathrm{CV}$ ) from the global mean. It is usually accepted that local wind measurements in 2 consecutive years lead to results acceptable for the annual wind speed quantification of the wind for characterization of wind energy potential.

Other studies (Raftery et al., 1997; Gardner et al., 2009) have proposed a value around 6\% for the CV of the AMWS of a single year around a long-term mean. This figure was based on observation from meteorological mast with more than 20 years of records spread out through Northern Europe including Great-Britain.

Industry's typical practice has been to use the figure proposed by Raftery et al., (1997) and Gardner et al. (2009) to represent interannual wind variability for sites, regardless of their actual location. This figure has been routinely accepted and seldom argued.

Additionally, the industry defines CV of sampled (or measured) $N$ years, $\sigma_{N}$, using the typical expression:

$\sigma_{N}=\frac{\sigma_{1}}{\sqrt{N}}$

where $\sigma_{1}$ is, as mentioned, usually based on the $\mathrm{CV}$ of $6 \%$.

\section{Methodology}

The study of the minimum acceptable period of measurements required to characterize the long-term wind regime of a site in Dobrogea region was carried out in two stages.
Initially, 10 local measurements masts were selected for this study. The period of observed data from those masts ranged from 3 to 5 years.

The study of the inter-annual variability was done by comparing the mean wind speed for the complete measurement period obtained for each location with the annual and consecutive biannual and triennial periods.

Even the larger available datasets could be considered too short for wind speed long-term characterization. To overcome this limitation the NCEP/NCAR Reanalysis 1 database was used.

The NCEP/NCAR R1 project, conceived by the National Oceanic and Atmospheric Administration (NOAA) and National Centre for Environmental Prediction (NCEP, part of the National Centre for Atmospheric Research), consists of on a global database of weather data generated by a global weather model using as various sources of weather observations (standard meteorological observations, buoys, satellites, and several others) (Kistler et al., 2001).

The period for which there is available data is large, ranging from 1948 to nowadays. The models run for a resolution of $2.5^{\circ} \times 2.5^{\circ}$ (about $300 \times 300 \mathrm{~km}$ ), and the data is provided by NOAA-CIRES Climate Diagnostics Center, Boulder, Colorado, EUA.

Results are available at $6 \mathrm{~h}$ intervals and produced on terrain following sigma coordinates, and concurrently derived to pressure levels. Due to the relatively coarse resolution of the model employed, the terrain height varies greatly within the grid node used, creating inconsistencies relevant to correlation techniques employed in the data analysis. To facilitate the statistical analysis when using Reanalysis data, it is therefore advisable to use data from pressure levels, since they are adjusted to a homogeneous surface.

The general purpose of conducting reanalysis dataset is to produce multiyear global state-of-the-art gridded representations of atmospheric states minimizing artificial trends that could arise from changing model settings or constant data assimilation system. Still, in NCEP/NCAR global reanalysis, the worldwide observation network has changed in the course of years.

Kanamitsu et al. (2002) executed a corrected version of R1, often called R2, covering only the satellite era from 1979 to the present.

Exhaustive descriptions of the NCEP/NCAR global reanalysis data are given by Kistler et al. (2001) and Kanamitsu et al. (2002).

Data for two NCEP/NCAR R1 grid points were selected and, for those locations, horizontal mean wind speeds for the last 20 years were extracted.

In Fig. 1 Romania's map with the geographical locations of measurement stations (MS) used in this work is shown. The

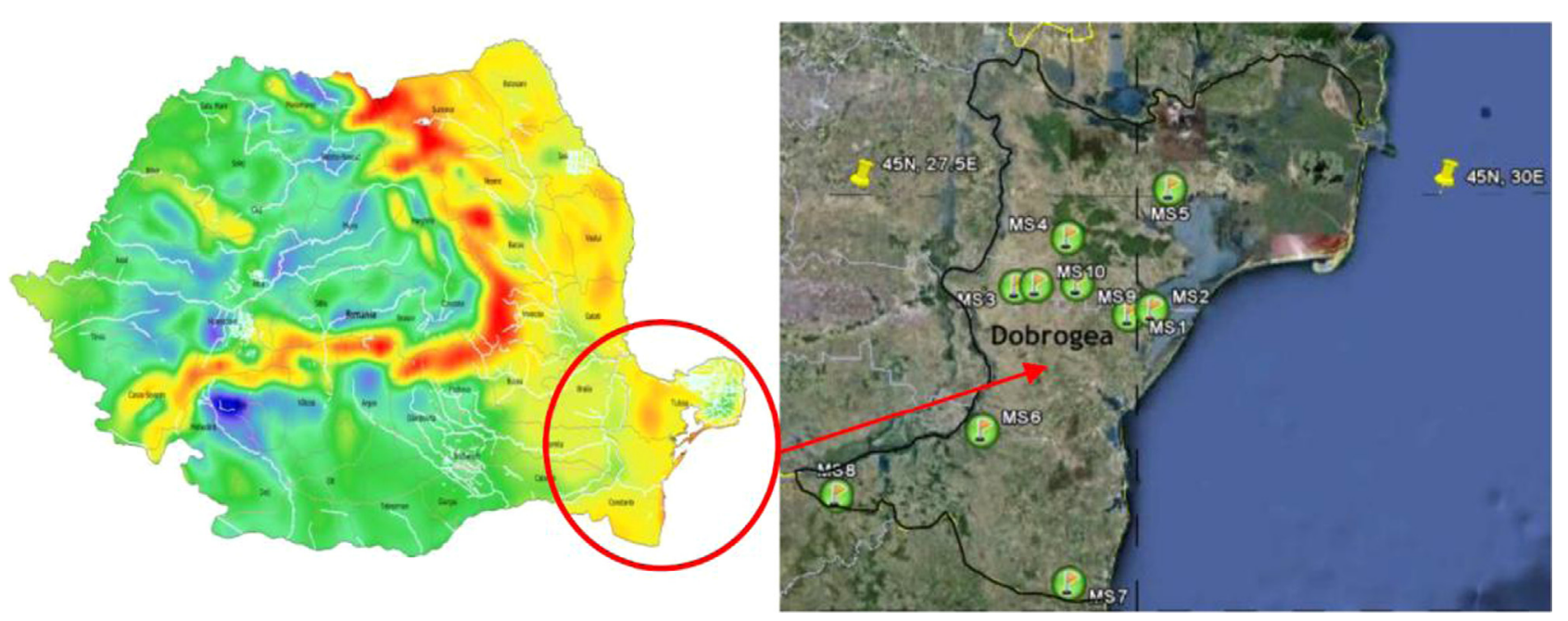

Fig. 1. Dobrogea region with location of the 10 local meteorological stations and NCEP/NCAR R1 grid points. 
coordinates of the NCEP/NCAR R1 grid points are also marked in this figure.

\section{Wind speed variability from local measurements}

All 10 masts selected for this study were primarily used for wind resource assessment and they are compliant with most of the guidelines developed for this purpose (Pedersen et al., 1999; IEC, 2005). The collected data is routinely scrutinized during the measurement campaign, insuring high quality of wind speed records.

Wind data available ranges from 3 to 5 years with a recovery rate of, at least, 86\%. Data was collected between 2006 and 2010.

For each set, the AMWS of the complete period of measurements and its coefficient of variance, CV (standard deviation expressed as a percent of mean value) were calculated. The CV, for 2 and 3 years were also investigated for cases with at least 4 years of data.

The results are presented in Table 1 . They indicate that the CV is similar across all the sites, with a mean value for the Dobrogea region of $3.9 \%$. A maximum annual wind variability of $6 \%$ was found for the 10 study locations. The lower value of CV for MS10 is related with the available measurement period (2008-2010). In fact, measurements have shown that, in the last 3 years there was no significant variation in the AMWS in opposition to the period between 2006 and 2008. For 2 and 3 consecutive years mean coefficient of variation values of $2.4 \%$ and $1.4 \%$, respectively, were found.

In Fig. 2 the maximum values obtained for the deviations from the overall AMWS for annual, biannual and triennial mean wind speeds for each analyzed meteorological station (MS1 to MS10) are displayed. All biannual and triennial periods correspond to periods with consecutive years.

In all sets it was found that increasing the number of years of measurement used in the calculation of the mean speed resulted in the reduction in the maximum deviation of the average speed at a given site.

Overall, data show that the amplitude of deviations around the AMWS is in the range from $-7.2 \%$ to $6.8 \%$ when using 1 year of data. This amplitude is reduced to a range from $-3.4 \%$ to $4.5 \%$ when 2 consecutive years of data are used. With 3 consecutive years of data the amplitude drops to $-3 \%$ to $2.3 \%$.

From one to 2 consecutive years of measurements, the minimum reductions in the maximum deviation from the mean for the global period were $1.1 \%$ and $1.6 \%$, in the case of mast MS10 and MS1 respectively, with the higher value found for meteorological station MS4, 8.2\%.

Considering one more consecutive year of measurements - a total of 3 years - the maximum deviation from the mean of global period led to a decrease of at least $0.7 \%$, case MS2, with the highest value of $5 \%$ found for meteorological station MS7.
Despite the consistency of results presented it should be pointed out that the size of the sampled data gradually decreases as the maximum deviations are calculated for consecutive increasing periods. Therefore, the consistency of the analysis presented decreased progressively.

\section{Validation of NCEP/NCAR R1 to assess the wind speed variability}

With the aim of improving the analysis of the inter-annual wind speed variability namely in what concerns to the measurements long-term length limitation, the capacity of the NCEP/NCAR Reanalysis R1 data to represent the inter-annual wind variations for the Dobrogea regions was assessed.

In fact, the larger sets of local data used, 5 years, could be considered too short for wind speed long-term characterization. Furthermore, the analysis was limited to 3 consecutive years also because of the limitation of the extension of the measuring periods. If NCEP/NCAR database could be used, the wind speed of the long-term could be achieved, for instance, from the mean of the last 20 years instead of the 5 years available from the local measurements.

First the NCEP/NCAR database for Dobrogea region must be validated. This section presents what was done to achieve this objective.

Every local set of data was associated with a data series of NCEP/NCAR R1 horizontal wind speed, extracted from the grid point, at a pressure level of $100 \mathrm{kPa}$, with the exact same data period, the closest to the local dataset. Two NCEP/NCAR R1 points were used: point $(45 \mathrm{~N} ; 27.5 \mathrm{E})$ and point $(45 \mathrm{~N} ; 30 \mathrm{E})$.

The NCEP/NCAR R1 data was synchronized with the local sets in order to share exactly the same amount of wind data in each case. This was done by disregarding the NCEP/NCAR data from the

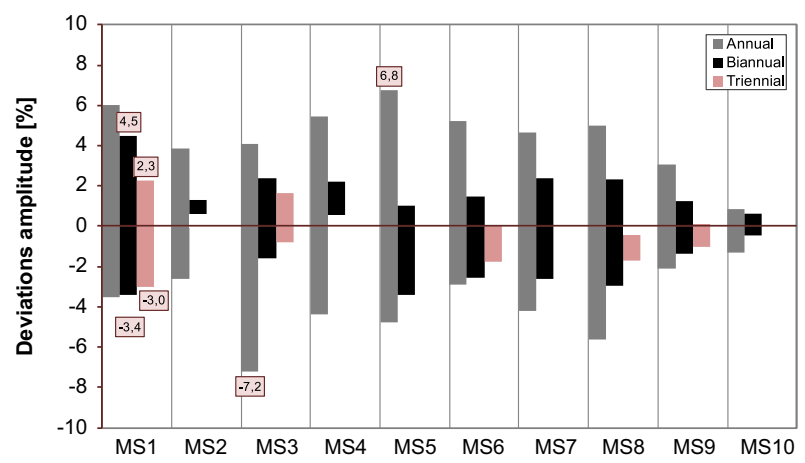

Fig. 2. Amplitude of the deviations of annual, biannual and triennial means to the overall AMWS for the 10 meteorological stations.

Table 1

CVs of annual, biannual and triennial mean wind speeds at 10 meteorological stations located in Dobrogea region.

\begin{tabular}{|c|c|c|c|c|}
\hline Station name & No of years data & $\begin{array}{l}\text { Coefficient of variation } \\
\text { (\% of AMWS) }\end{array}$ & $\begin{array}{l}\text { Coefficient of variation of the } \\
2 \text { years mean AMWS (\% of mean) }\end{array}$ & $\begin{array}{l}\text { Coefficient of variation of the } \\
3 \text { years mean AMWS (\% of mean) }\end{array}$ \\
\hline MS1 & 5 & 4.3 & 3.8 & 2.7 \\
\hline MS2 & 3 & 3.4 & & \\
\hline MS3 & 5 & 4.3 & 1.7 & 1.3 \\
\hline MS4 & 3 & 5.0 & & \\
\hline MS5 & 3 & 6.0 & & \\
\hline MS6 & 4 & 3.7 & 2.1 & 1.3 \\
\hline MS7 & 3 & 5.0 & & \\
\hline MS8 & 4 & 4.4 & 2.9 & 1.0 \\
\hline MS9 & 4 & 2.2 & 1.5 & 0.8 \\
\hline \multirow[t]{2}{*}{ MS10 } & 3 & 1.1 & & \\
\hline & Mean & 3.9 & 2.4 & 1.4 \\
\hline
\end{tabular}


months for which there was no monthly observations of the wind speeds at the meteorological stations. Through this, different NCEP/ NCAR R1 periods for each meteorological station were obtained.

The simultaneous data sets of the meteorological stations observations and reanalysis were then correlated in a monthly base. The results are presented in Table 2 .

The correlation coefficients are somewhat lower but still above 0.8 at most stations. The correlation coefficient dropped to as low as 0.7273 only for MS3. The higher values were found for MS5 and for MS7.

These results indicate that reanalysis data closely match the observed monthly wind speed variation.

For the years of operation of each measuring station, the mean wind speed of each year was calculated and its deviation (as a percentage) relatively to AMWS of the complete period of measurement was determined. The same procedure was used using the data from NCEP/NCAR of each station. In Figs. 3 and 4 the deviations obtained in each year using local wind measurements were plotted against the ones obtained using data from NCEP/NCAR.

These figures are divided into four quadrants.

Points located in the 1st quadrant (upper right) represent years in which the wind measurements and data from the NCEP/NCAR indicate mean wind speeds above the overall AMWS for the entire period, while the points in the 3rd quadrant (bottom left) indicate

Table 2

Linear correlation coefficients $(\mathrm{R})$ between meteorological stations and reanalysis data.

\begin{tabular}{lll}
\hline NCEP/NCAR simultaneous period with & Months of data & $R$ \\
\hline MS1 & 53 & 0.8520 \\
MS2 & 35 & 0.8521 \\
MS3 & 50 & 0.7273 \\
MS4 & 35 & 0.8534 \\
MS5 & 32 & 0.8742 \\
MS6 & 45 & 0.8380 \\
MS7 & 34 & 0.9071 \\
MS8 & 46 & 0.8609 \\
MS9 & 52 & 0.8429 \\
MS10 & 33 & 0.8154 \\
& Mean & $\mathbf{0 . 8 4 2 3}$ \\
\hline
\end{tabular}

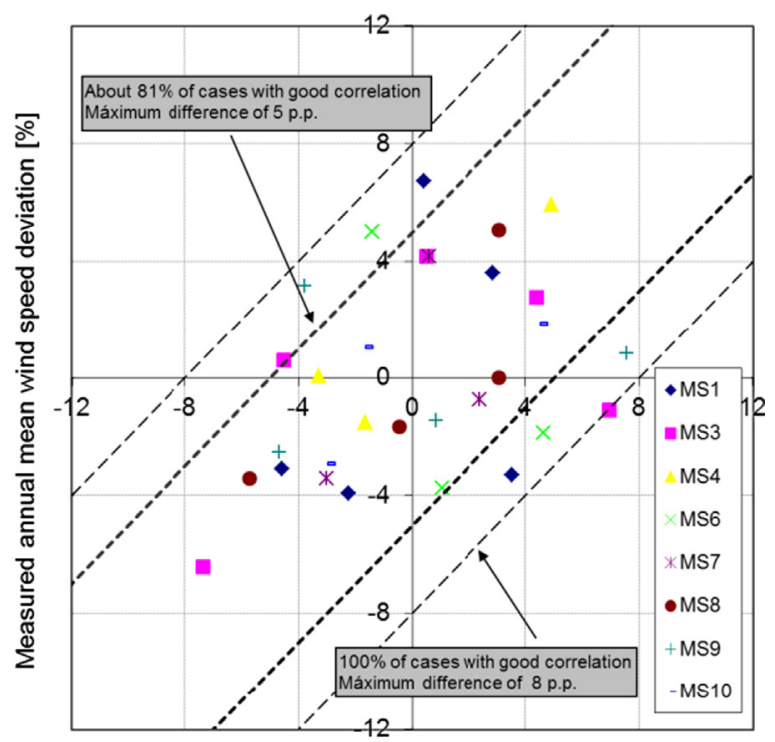

NCEP/NCAR annual mean wind speed deviation [\%]

Fig. 3. Comparison of the AMWS deviations relatively to the full period of measurements between the local stations and NCEP/NCAR data (Point 45N; 27.5E).

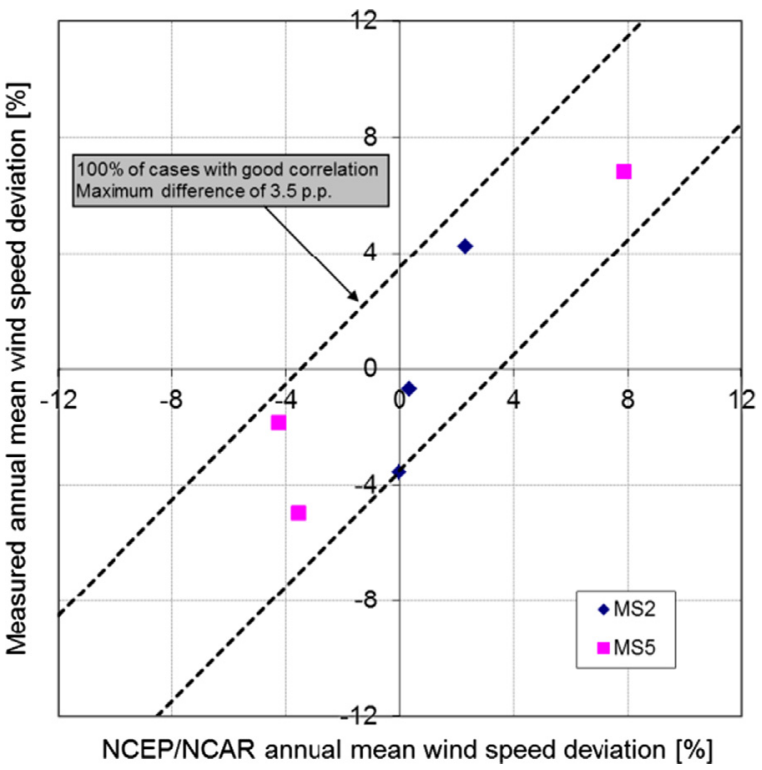

Fig. 4. Comparison of the AMWS deviations relatively to the full period of measurements between the local stations and NCEP/NCAR data (Point 45N; 30E).

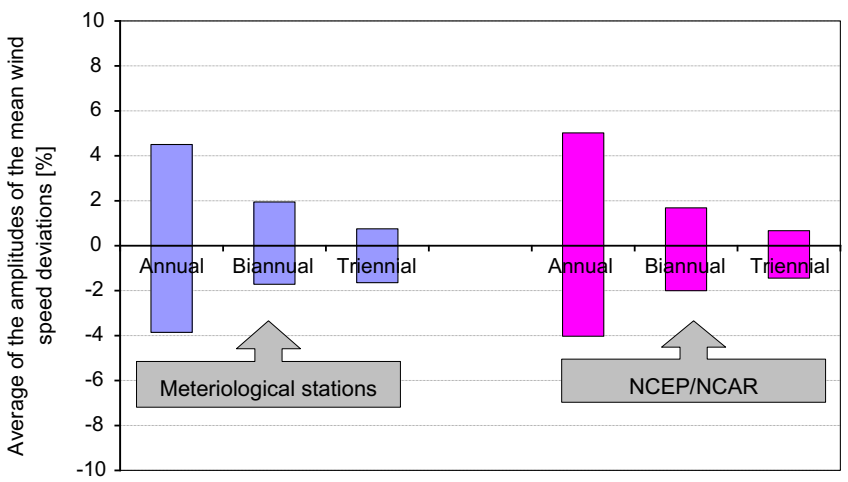

Fig. 5. Average of the maximum amplitudes of the deviations of the mean wind speed.

years in which annual means were below the overall AMWS in both datasets.

The 2nd (bottom right) and 4th (upper left) quadrants show the years where local wind measurements and NCEP/NCAR data indicate opposite trends for the deviation from the overall AMWS. That is, when measurements indicate the year is above average while NCEP/ NCAR data indicates the year is below average, or vice versa.

This scenario does not necessarily represent the worst fit between measurements and NCEP/NCAR database. In fact, although the trend can be opposite the difference between the values may be substantially less than cases in which the tendency is the same.

The results show that for the NCEP/NCAR grid coordinate $(45 \mathrm{~N} ; 27.5 \mathrm{E})$, the maximum difference observed between the deviations of the AMWS using measurements and database, is 8 percentage points. This value reduces to 5 percentage points in $81 \%$ of years analyzed considering all set of stations.

In the NCEP/NCAR grid point $(45 \mathrm{~N} ; 30 \mathrm{E})$ there were no differences of more than 3.5 percentage points between the annual deviations from mean wind speeds calculated with local data and data from the NCEP/NCAR for the same period.

A complementary analysis of the average amplitude of the maximum deviations of AMWS for the different averaging periods was also made in order to compare results for NCEP/NCAR R1 against those from the local masts. The summary of these results is shown in Fig. 5. 

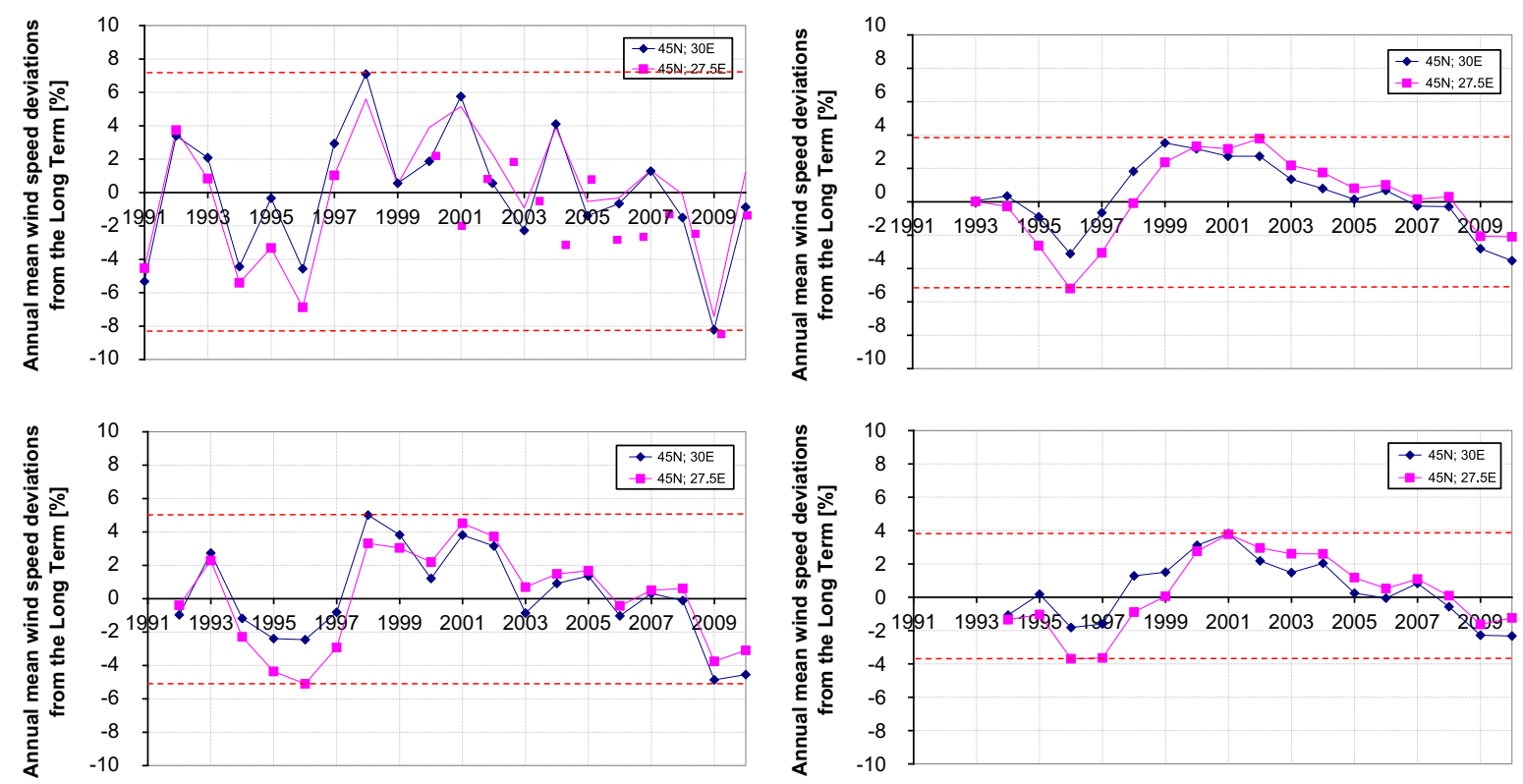

Fig. 6. Deviations of yearly to 4 years moving means wind speeds to the long-term AMWS, for both NCEP/NCAR points.

These findings emphasize the similar behavior between measurements and NCEP/NCAR data in what concerns to the average values of the maximum deviation of the annual, biannual and triennial mean wind speed. For both types of data, in addition to having obtained values with the same order of magnitude there is also the same downward trend with the increase of consecutive period studied.

Thus, on average, we obtained maximum deviations of the mean speed between $-4 \%$ and $5 \%$ when using one year of wind data, decreasing to a range of $-2 \%$ to $2 \%$ if taking into account two consecutive years. With a period of 3 years of wind data, the average of the maximum deviations is located in the interval $-1.6 \%$ to $0.8 \%$.

These results show that, for the vast majority of sites, the data from NCEP/NCAR translated the inter-annual variability of the wind regime in a similar way to that seen when we used the local measurements.

Assuming as sufficiently valid the conclusions found here, the analysis of the inter-annual wind speed variability proceed with only the reanalysis data, thus enabling the characterization of the long-term wind speed not only by the total period of measurements available at each location, but using the last 20 years of data from the NCEP/NCAR.

\section{Inter-annual wind speed variability from NCEP/NCAR R1 data base}

The 20 year period 1991-2010 from the NCEP/NCAR R1 data was used to assess the inter-annual wind speed variability at the Dobrogea region.

Although 30 year data is recommended for an accurate description of the climatology, it is also known that, within the last 30 years, the global weather observation network, used as input to the reanalysis global assimilation model, has suffered dramatic changes. This evolution is seen as a major source of artificial trends in the reanalysis data. For the region under study it is only after the early 1990s that the observational network has remained relatively constant (Raftery et al., 1997). For that reason the most recent 20 years were used. This is already an extended period of data that, compared with local observations of much shorter

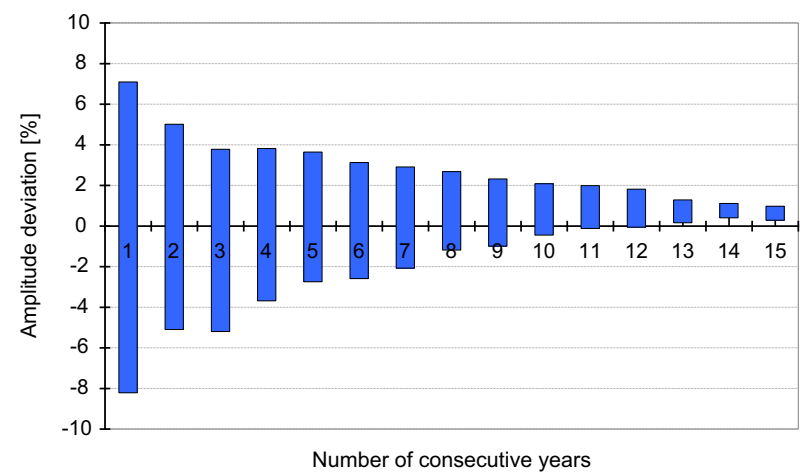

Fig. 7. Range of deviations to the long-term for both NCEP/NCAR points.

duration, will put the wind climate evolutions trends in a clear perspective of longer term.

The deviations to the 20 year (from now on referred to as longterm) AMWS of yearly to 4 years moving average wind speeds are present in Fig. 6 for both NCEP/NCAR R1 grid points.

Of the 20 years studied, half were periods with AMWSs clearly above the long-term being the 2009 the year when the mean wind speed was substantially lower, reaching a deviation of about $-8.5 \%$. The windiest year of the two decades was 1998 .

As expected, the results also show that as the continuous period of analysis enlarges the range of the deviations of the AMWS relatively to the long-term decrease and the scatter around the long-term average is smaller.

Considering the two NCEP/NCAR sets of data used in this study, Fig. 7 represents the evolution of the amplitude deviations to the long term AMWS as the consecutive calculating period increases from annual to 15 years moving means.

The results show a consecutive decrease in the amplitude values of the maximum deviation for all crescent periods analyzed.

However, it is clear that the reduction rate is significantly higher, around 34\%, when using 2 years of data instead of only one year: From 2 to 15 consecutive years of data the trend is also declining but at a significantly lower rate, about $16 \%$ on average.

Thus, the maximum deviations from the long-term fall in the range of $-8.5 \%$ to $6.8 \%$ when using 1 year data to calculate the 
Table 3

$\mathrm{CV}$ of annual mean wind speeds from $20 \mathrm{yr}$ Reanalysis data sets.

\begin{tabular}{|c|c|c|c|c|}
\hline $\begin{array}{l}\text { NCEP/NCAR grid } \\
\text { point }\end{array}$ & $\begin{array}{l}\text { No of years } \\
\text { data }\end{array}$ & $\begin{array}{l}\text { Coefficient of variation of long-term } \\
\text { AMWS (\% of mean) }\end{array}$ & $\begin{array}{l}\text { Coefficient of variation of the } 2 \text { years LT } \\
\text { AMWS (\% of mean) }\end{array}$ & $\begin{array}{l}\text { Coefficient of variation of the } 3 \text { years LT } \\
\text { AMWS (\% of mean) }\end{array}$ \\
\hline $45 \mathrm{~N} ; 30 \mathrm{E}$ & 20 & 3.8 & 2.7 & 2.1 \\
\hline $45 \mathrm{~N} ; 27.5 \mathrm{E}$ & 20 & 3.8 & 2.9 & 2.4 \\
\hline Mean & & 3.8 & 2.8 & 2.3 \\
\hline
\end{tabular}

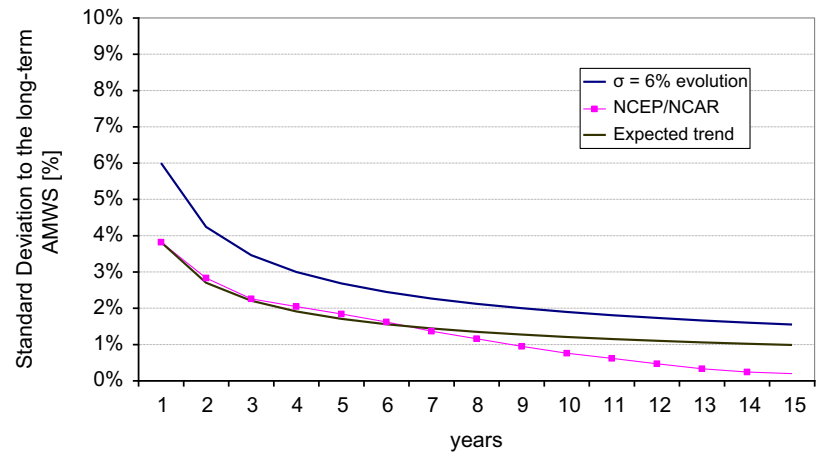

Fig. 8. CV as a function of the total number of years in the sample.

mean wind speed and decrease their values for the ranges from $-5.1 \%$ to $4.7 \%$ and $-5.2 \%$ to $3.8 \%$ when the number of consecutive years passes for two and three, respectively.

Interesting enough, the amplitude of deviations for 2 consecutive years seems to confirm the findings of Troen and Petersen (1989) which pointed to a maximum $+/-5 \%$ deviation around annual long term mean for 2 consecutive years.

The CV of the annual, biannual and triennial mean wind speeds at each NCEP/NCAR coordinate was also calculated and is presented as a percentage of long-term AMWS in Table 3. The ratios are similar for both points with averages of 3.8\%, $2.8 \%$ and $2.3 \%$ for one to 3 consecutive years.

\section{Comparison against industry standards}

The figure proposed for the CV of long-term AMWS for the Dobrogea region (3.8\%) differs substantially from the industry's typical $6 \% \mathrm{CV}$, pointing to a far lower inter-annual variability of wind intensities. This will automatically mean, in this respect, lower uncertainties on assessments made, namely with few years of local observations.

Fig. 8 compares the evolution of $\mathrm{CV}$ as a function of numbers of observed or sampled years based on:

i. expression (1) and a typical annual CV of $6 \%$ ( $6 \%$ evolution);

ii. expression (1) and a CV of 3.8\% taken from Table 3 (expected trend);

iii. the full NCEP/NCAR 20 years data set (NCEP/NCAR series).

As expected, the standard deviations representing the "6\% evolution" curve are all lower than the ones of "expected trend". The reason is only the higher 1 -year CV from which the trend is calculated. Both trend decrease rapidly in the initial years, attaining half of its initial values in 4 years.

Comparing the "expected trend" with "NCEP/NCAR" no significant differences are observed until the 7th year. Afterwards, the "NCEP/NCAR" trend is progressively less conservative with CV values less than $1 \%$.
The representativeness of the estimated annual production of a given wind farm depends on the quality and representativeness of wind data, modeling and/or wind regime estimates to the installation height of the rotor for the wind farm turbines and modeling and/or estimate of the future wind farm performance or efficiency.

Within the representativeness of wind data, the inter-annual variability of wind resource, namely in regards to the observational periods from wind resource assessment campaigns, plays a very important role.

An interesting output of the above findings is to quantify how does the length of local wind data (in number of years) impacts wind farm energy estimates uncertainty.

For the purpose of this exercise, a simple formulation for the uncertainty of annual energy production estimates of a wind farm $\left(u_{A E P}\right)$ can be given by the following expression:

$u_{A E P}=\sqrt{u_{\text {anemometer }}^{2}+u_{\text {present variability }}^{2}+u_{\text {future variability }}^{2}+u_{\text {model }}^{2}}$

where $u_{\text {anemometer }}$ is the uncertainty on the collected wind data caused by the instrumentation set-up, $u_{\text {present variability if the }}$ uncertainty from the inter-annual wind variability for the observed (present) wind data period, $u_{\text {future variability }}$ is the uncertainty from the inter-annual wind variability for the future wind farm operational period and $u_{\text {model }}$ is the uncertainty from wind and wind farm modeling.

$u_{\text {present variability }}$ and $u_{\text {future variability }}$ are based on the assumed inter-annual wind variability (or CV) and, typically, on expression (1). $u_{\text {present variability }}$ changes with length of collected local wind data while $\mathrm{u}_{\text {future }}$ variability is usually fixed at 10 or 20 years variability.

The inter-annual wind variability is assumed to be of $4 \%$ of AMWS, based on the above findings for the Dobrogea region (Table 3).

According to MEGAJOULE's experience in several wind farm projects, the sensitivity annual energy production to changes in wind speed, for an average utility size wind farm, typically varies between 1.7 and 2.5. Meaning that 5\% uncertainty in wind speed will represent a $8.5-12.5 \%$ uncertainty in wind farm annual energy yield. In Dobrogea sites, in particular, typical values for the mentioned sensitivity are closer to 2.0. This sensitivity is mostly dependent on frequency distribution of wind intensities and, thus, will change from site to site. A value of 2.0 was adopted in here for illustrative reasons.

It should also be noted that typical wind assessments comprise some kind of extrapolation of local wind data to Long Term (10 years or more) with the help of auxiliary reference wind data. Meaning that final yield estimates are based in longer datasets that measured ones, even if partially obtain with extrapolation. This extrapolation process also adds to the final uncertainty. In the example below we did not consider any Long Term extrapolation as not to disguise the impact of local measurement data length but one should realize that this will seldom be the case for real energy assessments.

The impact of changes in observational period on the uncertainty of annual energy production estimate is represented for an example case study of a $10 \mathrm{MW}$ wind farm in Dobrogea region 
Table 4

Uncertainty breakdown for the example case.

\begin{tabular}{lll}
\hline Uncertainty source & Uncertainty in $\mathbf{~ m / s}$ & Uncertainty in GW h \\
\hline$u_{\text {anemometer }}(\%)$ & 2.0 & 4.0 \\
$u_{\text {present variability }}(\%)$ & $\frac{4}{\sqrt{N}}$ & $2 \times \frac{4}{\sqrt{N}}$ \\
$u_{\text {future variability }}(10$ years) (\%) & 1.26 & 2.52 \\
$u_{\text {model }}$ & - & $8.00 \%$ \\
\hline
\end{tabular}

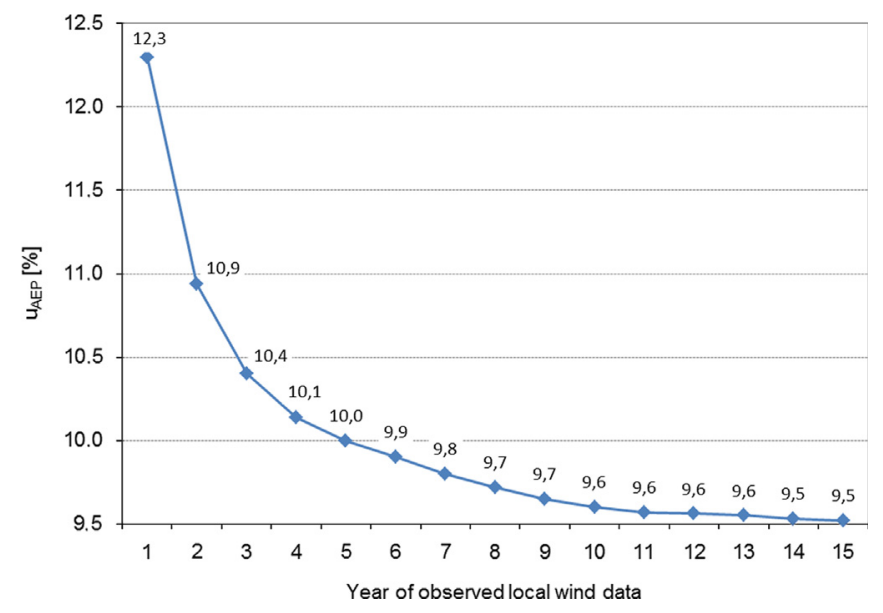

Fig. 9. Evolution of $\mathrm{u}_{A E P}$ with length of local wind data - example case study.

with uncertainty breakdown in Table 4. Fig. 9 shows the evolution of the overall $u_{\mathrm{AEP}}$ with the duration of the measured wind data.

Obviously that uncertainty figures depend strongly on the specific case in hands and, thus, the example here is merely illustrative. Still, even if the absolute values of $u_{A E P}$ is not very meaningful, the decrease in $u_{A E P}$ with the increase in length of wind data should be close to what can be expected, provided that a similar expression of uncertainty is followed.

As it can easily be seen, from the 1st to the 2nd year of measurements, the drop in overall uncertainty is above $1 \mathrm{pp}$ (percent point). For the next 5 years, the drop in uncertainty is much slower reaching only $2.6 \mathrm{pp}$ in the 10 th year.

Once again, the absolute overall uncertainty, uAEP, values used in the example are not very meaningful, as they always change significantly from site to site. Still, a conclusion that can be taken from this example is that, for this wind variability, from 5 years onwards, local wind data does not add much to uncertainty reduction and, so, if that would be the case, wind measurement could be terminated if necessary.

Unfortunately, one must recognize that length of measurement data is, almost invariably, determined by project development deadlines rather than final assessment uncertainty. Decision to terminate wind measurements is also never a simple economic judgment, as cost of continuing measurement campaigns is very small compared with all other project development costs. The figures above may allow some guidance for a better balance between project development pressure and final uncertainty in energy assessments.

\section{Conclusions}

The quantification of the wind potential of a site for energy use passes invariably by the study and characterization of its wind regime, usually described by the average speed and direction of wind and its variability in different scales.
This work presents the results of the inter-annual wind regime variability study for the Dobrogea region in Romania.

The main findings on this study are based on NCEP/NCAR R1 data previously validated for the Dobrodea region against local mast measurements. This data set seems to provide a good indication of inter-annual mean wind speed variability in this region.

As expected, the 20 years reanalysis datasets show a consecutive decrease in the amplitude of deviations around AMWS as crescent periods are used in the calculation of the mean speed. However, it is clear that the reduction rate is significantly higher when using 2 years of data instead of only one year (34\%). The extension of the datasets beyond the 2 consecutive years have a much lower impact, about $16 \%$ on average, on the AMWS deviations.

These results indicate that, for wind measurement campaigns in Dobrogea region, an addition of a 2nd year of measurements offers a significant reduction of wind variability. In fact, with such an extent of onsite wind records, the maximum deviation of the calculated annual mean wind speed to the long term is of the order of $5 \%$, compared to a maximum variability for 1 year of around $8 \%$. For many wind farms projects, the extension of the measurement campaign to a 2 nd year will be the most valuable choice. Extending the campaign to 3, 4 or 5 years only has an impact of subtracting around 1p.p. to this value.

The studied data also pointed out that the inter-annual variability of mean annual wind speed for the Dobrogea region could be much lower than wind industry standard figures. A value of 3.8\% for the CV of long-term mean speed was achieved against the typical industry value of $6 \%$.

Moreover, the evolution of inter-annual variability with the number of consecutive years of data appears slightly less conservative than the evolution typically assumed by the industry.

Changing the assumptions on inter-annual wind variability will change calculated uncertainty on wind farm energy estimates, with direct impact in investment and debt finance decisions.

In the example wind farm presented, gains in uncertainty reduction were significant up until a 5 year length of wind measurements.

Mentioned should be made to the use of consecutive years of wind data, as opposed to random years. Industry standard expression for wind variability as a function of the number of years assumes random and independent years, leading to slightly conservative results. Clarification on this expression was not pursued in this study but findings confirm that this could also prove a simple and effective improvement in the above mentioned uncertainty calculations.

The authors hope that this paper will allow some guidance for a better balance between project development pressure, and decision to terminate wind assessment campaigns, and final risk in energy assessments.

This study should be repeated for other regions with wind farm developments, quite specially those more distant from Central Europe/UK (where the industry standard practices were primarily derived). NCEP/NCAR reanalysis can be a very useful tool for this kind of studies (being freely available and global) but use for interannual wind variability should be tested in each case.

\section{References}

Gardner, P., Garrad, A., Hansen, L.F., Jamieson, P., Morgan, C., Murray, F., Tindal, A Crux, J. Arribas, L, Fichaux, N., 2009. Part I - Technology, Wind energy - The facts. A Guide to the Technology, Economics and Future of Wind Power. European Wind Energy Association, London, pp. 29-151.

IEC 61400, Part 12.1 Power Performance Measurements of Electricity Producing Wind Turbines, International Electrotechnical Commission, 2005. 
Kanamitsu, M., Ebisuzaki, W., Woollen, J., Yang, S.K., Hnilo, J.J., Fiorino, M., Potter, G. L., 2002. NCEP-DEO AMIP-II reanalysis (R-2). Bull. Am. Meteorol. Soc. 83, 1631-1643.

Kistler, R., Kalnay, E., Collins, W., Saha, S., White, G., Woollen, J., Chelliah, M., Ebisuzaki, W., Kanamitsu, M., Kousky, V., van den Dool, H., Jenne, R., Fiorino, M., 2001. The NCEP/NCAR 50-year reanalysis. Bull. Am. Meteorol. Soc, 82 (2), 247-268.

Pedersen, B.M., Pedersen, T.F., Klug, H., Van der Borg, N., Kelley, N., Dahlberg, J.A. 1999. Wind speed measurement and use of cup anemometry, Recommended
Practices for Wind Turbine Testing and Evaluation - International Energy Agency. Renewable Energy Systems Ltd, United Kingdom.

Raftery P., Tindal A., Garrad A., 1999. Understanding the risks of financing wind farms. In: Proceedings of EWEA - European Wind Energy Conference, 1-5 March, Nice, France, 1999, pp. 446-499 (ou Dublin, 1997).

Troen, Ib, Petersen, E.L., 1989. European Wind Atlas. Riso National Laboratory, Roskilde, Denmark. 